\title{
Does social disadvantage affect the validity of self-report for cervical cancer screening?
}

This article was published in the following Dove Press journal:

International Journal of Women's Health

21 January 2013

Number of times this article has been viewed

\author{
Aisha K Lofters ${ }^{1-3}$ \\ Rahim Moineddin ${ }^{1,4,5}$ \\ Stephen W Hwang 3,6 \\ Richard H Glazier ${ }^{1-3,4,5}$ \\ 'Department of Family and \\ Community Medicine, University of \\ Toronto, Toronto, ${ }^{2}$ Department of \\ Family and Community Medicine, \\ St Michael's Hospital, Toronto, ${ }^{3}$ Centre \\ for Research on Inner City Health, \\ The Keenan Research Centre in the \\ Li Ka Shing Knowledge Institute of \\ St Michael's Hospital, Toronto, \\ ${ }^{4}$ Institute for Clinical Evaluative \\ Sciences, Toronto, ${ }^{5}$ Dalla Lana \\ School of Public Health, University \\ of Toronto, Toronto, ${ }^{6}$ Department \\ of Medicine, University of Toronto, \\ Toronto, ON, Canada
}

Objective: The aim was to review the international literature on the validity of self-report of cervical cancer screening, specifically of studies that made direct comparisons among women with and without social disadvantage, based on race/ethnicity, foreign-born status, language ability, income, or education.

Method: The databases of Medline, EBM Reviews, and CINAHL from 1990 to 2011 were searched using relevant search terms. Articles eligible for data extraction documented the prevalence of cervical cancer screening based on both self-report and an objective measure for women both with and without at least one measure of social disadvantage. The report-to-record ratio, the ratio of the proportion of study subjects who report at least one screening test within a particular time frame to the proportion of study subjects who have a record of the same test within that time frame, was calculated for each subgroup.

Results: Five studies met the extraction criteria. Subgroups were based on race/ethnicity, education, and income. In all studies, and across all subgroups, report-to-record ratios were greater than one, indicative of pervasive over-reporting.

Conclusion: The findings suggest that objective measures should be used by policymakers, researchers, and public-health practitioners in place of self-report to accurately determine cervical cancer screening rates.

Keywords: vulnerable populations, early detection of cancer, vaginal smears, Pap test, reproducibility of results, validity

\section{Introduction}

Detection of invasive cervical cancer by screening confers a better prognosis and improved survival compared with cervical cancer being detected symptomatically. ${ }^{1}$ This effect is not attributable to lead-time bias, and is largely due to screen-detected cancers being found at earlier stages than symptomatic cancers. ${ }^{1}$ Due to the clear benefits of cervical cancer screening, and the potential harms when screening is inadequate, policy makers, researchers, and public-health practitioners need valid methods of determining Papanicolaou (Pap) test rates. Underestimation of rates could lead to policies and programs that make inappropriate use of resources, and overestimation could lead to missed opportunities to increase screening. ${ }^{2,3}$ Self-report of previous tests is a commonly used and relatively easy method to determine prevalence of cancer screening for policymakers and knowledge users, but its validity has been questioned in the literature. ${ }^{4-7}$

Women with certain sociodemographic characteristics have been found to be underscreened for cervical cancer, including racial/ethnic minorities, immigrants, women of
Correspondence: Aisha Lofters St Michael's Hospital Dept of Family and Community Medicine, University of Toronto, 30 Bond Street, Toronto, ON M5B IW8, Canada

Tel + I 4168677428

Fax + I 4168677498

Email aisha.lofters@utoronto.ca 
low income, and those with low educational attainment. ${ }^{8-15}$ The determination of accurate screening rates is of particular importance for women in these groups, to allow for accurate monitoring and evaluation of targeted interventions. ${ }^{16-18}$ However, the validity of self-report may be of particular concern for these same groups, and the literature is not clear on the subject. For example, the tendency to give socially desirable responses may be higher among those with less education and among non-White survey respondents, but lower among the unscreened. ${ }^{19}$ As well, previous reviews of the literature have suggested that Hispanic and AfricanAmerican women disproportionately over-report Pap test screening compared with their White counterparts, ${ }^{3,7}$ and contradictorily, that minority or low socioeconomic status is not associated with accuracy of Pap test recall. ${ }^{6}$ The purpose of this study is to review the international literature on the validity of self-report of cervical cancer screening, with a specific focus on studies that make direct comparisons of validity among women with and without social disadvantage.

\section{Methods}

The databases of Medline, EBM Reviews, and CINAHL from 1990 to 2011 were searched using the search terms "self report," "cancer screening," "early detection of cancer," "vaginal smears," "Pap test," "reproducibility of results," and "validity". The search was limited to articles published in English. The reference lists of previous literature reviews ${ }^{3,6,7,20}$ were also searched to identify studies that may have been missed. This strategy produced 114 unique articles. After review of the titles and abstracts, the authors were left with 24 studies that appeared to validate self-report of cervical cancer screening against an objective measure. The full text of the articles was then reviewed to determine which were eligible for data extraction. Articles eligible for data extraction had to: (1) include the prevalence of cervical cancer screening based on both self-report and an objective measure, ie, medical charts, administrative data, laboratory reports, and/or a cytology registry, for the same women within the same time frame, and (2) had to do so for both women with and without at least one of the chosen measures of social disadvantage. Specifically, social disadvantage was defined based on any of the following: income, education, race/ethnicity, language ability, and foreign-born status. No geographic limitations were set on the literature search.

Five studies met the extraction criteria. ${ }^{21-25}$ Of note, one

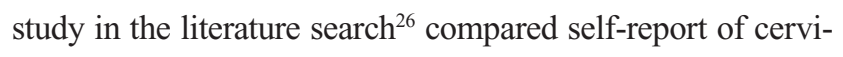
cal cancer screening with medical records for women from each of five racial/ethnic groups; however, the study sample only included women who reported a Pap test, meaning the prevalence of positive self-report was artificially set at $100 \%$. Therefore, this study was excluded from this review. The following data were extracted from all studies meeting the selection criteria: setting, number and age range of women in the validation sample, objective measure used, time frame for recall, and the sociodemographic groups that were compared.

The report-to-record ratio, the ratio of the proportion of study subjects who report at least one screening test within a particular time frame to the proportion of study subjects who have a record of the same test within that time frame, is frequently used as a measure of net bias of self-report, with values greater than one indicating over-reporting and values less than one indicating under-reporting. ${ }^{27}$ Therefore, for each study subgroup, a report-to-record ratio was calculated. SAS version 9.3 (SAS Institute, Cary, NC) was used for all confidence interval calculations.

\section{Results}

The five included studies varied widely in the setting, number and age range of included women, and time frame for recall $^{21-25}$ (Table 1). Four were performed in the US, and one was conducted in Ontario, Canada. ${ }^{24}$ One study was done at the population level, ${ }^{24}$ whereas the remainder had sample sizes ranging from 251 to 4784 women. Three studies ${ }^{21,23,25}$ compared self-report with medical charts and two ${ }^{22,24}$ with administrative data. Four studies ${ }^{21-23,25}$ created subgroups based on race/ethnicity, one ${ }^{21}$ categorized based on educational attainment, and one ${ }^{24}$ on neighborhood income quintiles (one study ${ }^{21}$ examined both race/ethnicity and education). No studies examined language ability or foreign-born status.

In all studies, and across all subgroups, report-to-record ratios were greater than one, indicative of pervasive overreporting (Figure 1). Over-reporting was especially high in the study with the oldest population, which also had the lowest screening rates. ${ }^{22}$ Confidence intervals for women with social disadvantage frequently overlapped with confidence intervals for those without, with one exception: ${ }^{22}$ where minority women had much higher report-to-record ratios. In general, the highest report-to-record ratios were not associated with any particular subgroup, but were associated with low values for the denominator (objective records of Pap tests). The considerable heterogeneity between the five studies precluded meta-analysis.

\section{Discussion}

In this review of studies that allowed for direct comparison of self-report validity of cervical cancer screening for 
Table I Description of the five studies meeting inclusion criteria

\begin{tabular}{|c|c|c|c|c|c|c|c|}
\hline Study & Study setting & $\begin{array}{l}\text { Time frame } \\
\text { for recall }\end{array}$ & $\begin{array}{l}\text { Age } \\
\text { range }\end{array}$ & $\begin{array}{l}\text { Self-report } \\
\text { measure }\end{array}$ & $\begin{array}{l}\text { Objective } \\
\text { measure }\end{array}$ & $\begin{array}{l}\text { Comparison } \\
\text { groups }\end{array}$ & $\mathbf{n}$ \\
\hline Caplan et $\mathrm{al}^{21}$ & $\begin{array}{l}\text { Health maintenance } \\
\text { organization in } \\
\text { Colorado, USA }\end{array}$ & 3 years & $40-74$ & $\begin{array}{l}\text { Telephone } \\
\text { survey }\end{array}$ & Medical chart & $\begin{array}{l}\text { Minority } \\
\text { White } \\
\text { Hispanic } \\
\text { Non-hispanic } \\
<\text { high school } \\
\geq \text { high school }\end{array}$ & $\begin{array}{l}40 \\
405 \\
36 \\
407 \\
33 \\
411\end{array}$ \\
\hline Fiscella et $\mathrm{a}^{22}$ & Throughout USA & I year & $65+$ & $\begin{array}{l}\text { In-person } \\
\text { interview }\end{array}$ & $\begin{array}{l}\text { Administrative } \\
\text { data }\end{array}$ & $\begin{array}{l}\text { Minority } \\
\text { White }\end{array}$ & $\begin{array}{l}634 \\
4150\end{array}$ \\
\hline Hiatt et $\mathrm{al}^{23}$ & $\begin{array}{l}\text { Health maintenance } \\
\text { organization in } \\
\text { California, USA }\end{array}$ & 2 years & $35-74$ & $\begin{array}{l}\text { Telephone } \\
\text { survey }\end{array}$ & Medical chart & $\begin{array}{l}\text { Hispanic } \\
\text { White }\end{array}$ & $\begin{array}{l}398 \\
288\end{array}$ \\
\hline Wang et $\mathrm{a}^{24}$ & $\begin{array}{l}\text { Throughout Ontario, } \\
\text { Canada }\end{array}$ & 3 years & $18+$ & $\begin{array}{l}\text { Telephone } \\
\text { survey }\end{array}$ & $\begin{array}{l}\text { Administrative } \\
\text { data }\end{array}$ & $\begin{array}{l}\text { Q1 (lowest income) } \\
\text { Q2 } \\
\text { Q3 } \\
\text { Q4 } \\
\text { Q5 }\end{array}$ & $\begin{array}{l}\text { Not provided; } \\
\text { population-level }\end{array}$ \\
\hline $\begin{array}{l}\text { Tumiel-Berhalter } \\
\text { et } \mathrm{al}^{25}\end{array}$ & $\begin{array}{l}\text { Two family practice } \\
\text { clinics in Buffalo, } \\
\text { New York, USA }\end{array}$ & 3 years, ever & $40+$ & $\begin{array}{l}\text { In-person } \\
\text { interview }\end{array}$ & Medical chart & $\begin{array}{l}3 \text { years } \\
\text { African-American } \\
\text { Puerto Rican } \\
\text { White } \\
\text { Ever } \\
\text { African-American } \\
\text { Puerto Rican } \\
\text { White }\end{array}$ & $\begin{array}{l}95 \\
96 \\
60 \\
112 \\
117 \\
75\end{array}$ \\
\hline
\end{tabular}

women with and without social disadvantage, it was found that over-reporting of screening is widespread, regardless of sociodemographic characteristics. The small number of heterogenous studies eligible for review precludes firm conclusions about differential rates of over-reporting by socio- demographic status. Of note, the study that was excluded ${ }^{26}$ similarly found that only $69.4 \%$ of self-reported Pap tests were validated in medical records, with a range of $65.9 \%$ for Latina women to $85.1 \%$ for White women. These findings suggest that health equity researchers, public-health

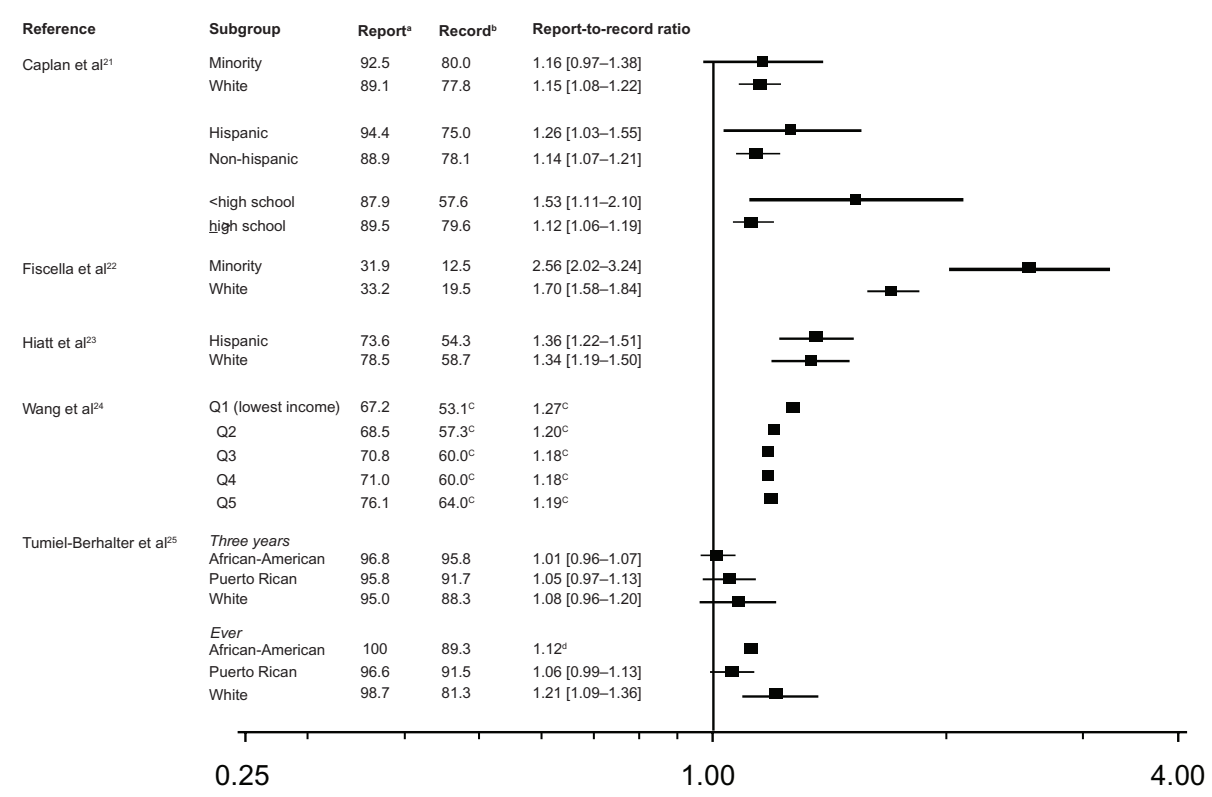

Figure I Report-to-record ratios by study and comparison groups.

Notes: aPercentage of women who reported a Pap test during the outcome time frame; bercentage of women who had a Pap test recorded during the outcome time frame; 'sample size not provided; therefore unable to calculate confidence intervals; 'unable to calculate confidence intervals due to lack of convergence. 
practitioners, and policy makers must interpret the accuracy of screening rates and screening gaps based on self-report with caution. The finding of widespread over-reporting, particularly when prevalence was low, ${ }^{22}$ is likely applicable to other kinds of cancer screening and preventive health maneuvers, and this possibility should be explored in similar reviews of the literature.

This review makes several contributions to the literature. To the authors' knowledge, this review is the first to identify studies that made direct comparisons of cervical cancer screening validity for women with and without social disadvantage. The study reviewed the international literature and investigated measures of social disadvantage beyond race/ ethnicity. It has also highlighted gaps in the literature that need to be addressed. Only a small number of studies were found, most of which had small sample sizes of disadvantaged women. These small sample sizes may in some cases have led to wider and overlapping confidence intervals. There were no studies assessing self-report validity for foreign-born women. Considering the ethnically and socioeconomically diverse nature and the high population of immigrants in many countries, more research studies need to be done to validate self-report for this vulnerable group, especially as known screening inequities may be larger than what would be suggested by self-report.

This review also has limitations. Two different objective measures were used in the included studies, and neither are necessarily perfect gold standards. Medical charts may miss some screening tests, as health care providers may not always record them properly, ${ }^{28}$ and administrative data also may not capture all screening tests..$^{24,29}$ As well, socially disadvantaged women may be more likely to visit health centers where physicians are salaried and have less motivation for accurate administrative documentation. ${ }^{3,22,26}$ However, as these measures are recorded at the time of screening, they are still expected to be more accurate, and more appropriate gold standards, than self-report. As well, the findings held regardless of the type of objective measure used. There were only a small number of studies in the review, with noticeable heterogeneity, precluding a meta-analysis. However, it was possible to calculate report-to-record ratios and confidence intervals for all studies. The paucity of available literature suggests that more studies need to be conducted to address this important research question.

Despite these limitations, the findings suggest that objective measures, such as medical charts, administrative data, laboratory records, or cytology registries, may be better than surveys or questionnaires to more accurately determine both cervical cancer screening rates and the magnitude of screening inequities. Using objective measures also circumvents the issue of response bias. Self-report rates can only be provided for women who agree to report. In situations where there is funding available and support at the policymaker level, organized screening programs linked to complete population-level cytology registries could lead to both more accurate determination of screening rates and gaps, and greater opportunities to increase screening for disadvantaged women. Where such organized programs exist, the infrastructure should be put in place to ensure that screening rates for the general population and for particular subgroups are determined directly from objective measures provided by the program itself. Such programs would also allow for true gold standards for determining screening rates. Of note, neither of the two countries where the included studies took place currently have national organized screening programs.

Where funds for such programs may not be available, and where self-report may be the method chosen due to feasibility or cost, especially when there is limited access to administrative data, ways of improving the accuracy of self-report through improving the wording and structure of surveys needs to be explored. ${ }^{3,24}$ When possible, researchers should conduct validation studies aimed at determining the requisite mathematical correction factors for various jurisdictions and sociodemographic groups if applicable. With more accurate measures of cervical cancer screening, researchers, primary-care providers, and policymakers will better be able to efficiently and effectively address the screening inequities that exist for disadvantaged women.

\section{Disclosure}

The authors report no conflicts of interest in this work.

\section{References}

1. Andrae B, Andersson TM, Lambert PC, et al. Screening and cervical cancer cure: population based cohort study. BMJ. 2012;344:e900.

2. Matthews BA, Nattinger AB, Anderson RC. Accuracy and certainty of self-report for colorectal cancer screening among ambulatory patients. Psychol Health Med. 2005;10(1):1-15.

3. Burgess DJ, Powell AA, Griffin JM, Partin MR. Race and the validity of self-reported cancer screening behaviors: development of a conceptual model. Prev Med. 2009;48(2):99-107.

4. Insinga RP, Glass AG, Rush BB. Pap screening in a US health plan. Cancer Epidemiol Biomarkers Prev. 2004;13(3):355-360.

5. Fiscella K, Franks P, Meldrum S. Estimating racial/ethnic disparity in mammography rates: it all depends on how you ask the question. Prev Med. 2004;39(2):399-403.

6. Howard M, Agarwal G, Lytwyn A. Accuracy of self-reports of Pap and mammography screening compared to medical record: a meta-analysis. Cancer Causes Control. 2009;20(1):1-13.

7. Rauscher GH, Johnson TP, Cho YI, Walk JA. Accuracy of selfreported cancer-screening histories: a meta-analysis. Cancer Epidemiol Biomarkers Prev. 2008;17(4):748-757. 
8. Amankwah E, Ngwakongnwi E, Quan H. Why many visible minority women in Canada do not participate in cervical cancer screening. Ethn Health. 2009;14(4):337-349.

9. McDonald JT, Kennedy S. Cervical cancer screening by immigrant and minority women in Canada. J Immigr Minor Health. 2007;9(4): 323-334.

10. Blackwell DL, Martinez ME, Gentleman JF. Women's compliance with public health guidelines for mammograms and pap tests in Canada and the United States: an analysis of data from the Joint Canada/United States Survey of Health. Womens Health Issues. 2008;18(2):85-99.

11. Woltman KJ, Newbold KB. Immigrant women and cervical cancer screening uptake: a multilevel analysis. Can J Public Health. 2007; 98(6):470-475.

12. Peterson NB, Murff HJ, Cui Y, Hargreaves M, Fowke JH. Papanicolaou testing among women in the southern United States. J Womens Health (Larchmt). 2008;17(6):939-946.

13. Barghouti FF, Takruri AH, Froelicher ES. Awareness and behavior about Pap smear testing in family medicine practice. Saudi Med J. 2008;29(7):1036-1040.

14. Moser K, Patnick J, Beral V. Inequalities in reported use of breast and cervical screening in Great Britain: analysis of cross sectional survey data. BMJ. 2009;338:b2025.

15. De Alba I, Sweningson JM. English proficiency and physicians' recommendation of Pap smears among Hispanics. Cancer Detect Prev. 2006;30(3):292-296.

16. Lofters AK, Moineddin R, Hwang SW, Glazier RH. Low rates of cervical cancer screening among urban immigrants: a population-based study in Ontario, Canada. Med Care. 2010;48(7):611-618.

17. Gakidou E. Coverage of cervical cancer screening in 57 countries: low average levels and large inequalities. PLoS Med. 2008;5(6):e132.

18. Moser K, Patnick J, Beral V. Inequalities in reported use of breast and cervical screening in Great Britain: analysis of cross sectional survey data. BMJ. 2009;338:b2025.

19. Vernon SW, Abotchie PN, McQueen A, White A, Eberth JM, Coan SP. Is the accuracy of self-reported colorectal cancer screening associated with social desirability? Cancer Epidemiol Biomarkers Prev. 2012; 21(1):61-65
20. Newell SA, Girgis A, Sanson-Fisher RW, Savolainen NJ. The accuracy of self-reported health behaviors and risk factors relating to cancer and cardiovascular disease in the general population: a critical review. $\mathrm{Am}$ J Prev Med. 1999;17(3):211-229.

21. Caplan LS, McQueen DV, Qualters JR, Leff M, Garrett C, Calonge N. Validity of women's self-reports of cancer screening test utilization in a managed care population. Cancer Epidemiol Biomarkers Prev. 2003;12(11 Pt 1):1182-1187.

22. Fiscella K, Holt K, Meldrum S, Franks P. Disparities in preventive procedures: comparisons of self-report and Medicare claims data. $B M C$ Health Serv Res. 2006;6:122.

23. Hiatt RA, Perez-Stable EJ, Quesenberry C Jr, Sabogal F, Otero-Sabogal R, McPhee SJ. Agreement between self-reported early cancer detection practices and medical audits among Hispanic and non-Hispanic white health plan members in northern California. Prev Med. 1995;24(3) 278-285.

24. Wang L, Jason XN, Upshur RE. Determining use of preventive health care in Ontario: Comparison of rates of 3 maneuvers in administrative and survey data. Can Fam Physician. 2009;55:178-179.e5.

25. Tumiel-Berhalter LM, Finney MF, Jaen CR. Self-report and primary care medical record documentation of mammography and Pap smear utilization among low-income women. J Natl Med Assoc. 2004;96(12): $1632-1639$

26. McPhee SJ, Nguyen TT, Shema SJ, et al. Validation of recall of breast and cervical cancer screening by women in an ethnically diverse population. Prev Med. 2002;35(5):463-473.

27. Warnecke RB, Sudman S, Johnson TP, O'Rourke D, Davis AM, Jobe JB Cognitive aspects of recalling and reporting health-related events: Papanicolaou smears, clinical breast examinations, and mammograms Am J Epidemiol. 1997;146(11):982-992.

28. Diamond CC, Rask KJ, Kohler SA. Use of paper medical records versus administrative data for measuring and improving health care quality: are we searching for a gold standard? Dis Manag. 2001;4(3):121-130.

29. Thompson BL, O'Connor P, Boyle R, et al. Measuring clinical performance: comparison and validity of telephone survey and administrative data. Health Serv Res. 2001;36(4):813-825.
International Journal of Women's Health

\section{Publish your work in this journal}

The International Journal of Women's Health is an international, peerreviewed open-access journal publishing original research, reports, editorials, reviews and commentaries on all aspects of women's healthcare including gynecology, obstetrics, and breast cancer. The manuscript management system is completely online and includes

\section{Dovepress}

a very quick and fair peer-review system, which is all easy to use. Visit http://www.dovepress.com/testimonials.php to read real quotes from published authors. 